JOAQUIN ARCE

\title{
El conocimiento de la Literatura italiana en la España de la segunda mitad del siglo XVIII
}

1.-No es fácil abordar en conjunto, globalmente, un tema que se adapta mejor al dato erudito aislado, a la mera referencia bibliográfica y del que interesan, sin embargo, más las consecuencias que el acarreo del material. Mi intención es releer lo que sobre el influjo o presencia de la literatura italiana en la España dieciochesca se ha escrito para ver si, integrado con nuevas aportaciones, podemos llegar a unas conclusiones no rutinarias, válidas según el estado actual de estos estudios.

En general, este tipo de trabajos han pecado de minuciosidad en la búsqueda, con el riesgo consiguiente de desviar la atención hacia el elemento de cultura disgregado, que adquiere aparentemente un relieve no justificable en el 
conjunto. No se trata de establecer coincidencias, paralelos o parecidos, de comprobar citas fragmentarias o estudiar determinadas polémicas y ni siquiera de documentar la presencia de extranjeros en España o de considerar las relaciones de viajeros españoles por Europa. Todo lo cual puede tener un innegable interés por sí mismo, pero de poco servirá a nuestros fines si no deducimos de ello en qué grado pudo haber calado en la cultura, la vida o la sensibilidad española de la época.

Leandro Fernández Moratín, al sintetizar los estudios de su padre referidos a la composición poética, afirma que, con la imitación de los poetas españoles, había emulado el método y doctrina de los franceses, junto a la fantasía y "sonido armónico" de los italianos. ${ }^{1}$ Sin proponérselo quizás, dejaba Leandro constancia del carácter predominante asignado a la poesía italiana por los españoles de la Ilustración. Carácter no alejado del señalado por Feijoo, cuando consideraba en su Paralelo de las lenguas castellana $y$ francesa, que "la lengua italiana suena mejor que las demás en la poesía"; ni de la advertencia añadida por Iriarte a su poema La Música, probando que la toscana, seguida del castellano, es la lengua más adecuada al canto. En la misma línea, pero acentuando los tonos, se halla Vargas Ponce cuando se refiere a "la femenil y muelle pronunciación", si bien "es verdad que aquella misma blandura y molicie, manejadas por un Ariosto, un Tasso, un Chiabrera, un Metastasio, embargan nuestros sentidos y se meten allá en lo íntimo del corazón". 2 Jovellanos, por su parte, sin aludir a Italia, afirmaba que la doctrina francesa era más universal y metódica y más ligada a intereses políti-

1. Obras de Don Nicolás y de Don Leandro Fernández de Moratín, B. A. E., II, pág. XIX.

2. Declamación contra los abusos introducidos en el castellano, Madrid, Ibarra, 1793, págs. 95.96. 
cos, mientras la inglesa, más original y profunda, se adaptaba mejor al genio español. ${ }^{3}$

Estamos, pues, asistiendo a una valoración global de culturas extranjeras, a unas caracterizaciones doctrinales y lingüísticas que tienen su peso en las corrientes literarias de la época. Si la exactitud y universalidad francesas encuentran su cauce apropiado en la poesía de la Ilustración, y si la originalidad y exotismo ingleses serán uno de los elementos más caracterizados de la sensibilidad prerromántica, la musicalidad y el sentido formal del italiano se hallarán en la base del gusto rococó y neoclásico. ${ }^{4}$

2.-La obra básica que sirve de punto de partida para el estudio de las relaciones literarias entre Italia y España en el siglo XVIII remonta al año 1896 y se debe al erudito italiano Vittorio Cian. ${ }^{5} \mathrm{Y}$ no sólo por lo que significó en sí, sino además por haber merecido la atención de los dos máximos investigadores que estaban en condiciones, en ambas naciones y en aquel momento, de integrar con nuevos datos lo que podía habérsele escapado al autor de la monografía italiana. Me refiero a las sendas recensiones que publicaron Menéndez Pelayo y Farinelli en 1896 y 1897 respectivamente. $^{6}$

Cian no se limita a la exposición documentada de la vida y escritos del mayor hispanista italiano del Sete-1

3. Memoria sobre educación pública, o sea, Tratado teórico-práctico de enseñanza, B. A. E., 46, pág. 248.

4. Sobre estos conceptos, cfr. Joaquín Arce, Rococó, Neoclasicismo y Prerromanticismo en la poesía española del siglo XVIII, en El Padre Feijóo y su siglo, "Cuadernos de la cátedra Feijoo", n. ${ }^{\circ}$ 18, vol. II, págs. 447-477.

5. Italia e Spagna nel secolo XVIII. Giovambattista Conti e alcune relazioni letterarie fra l'Italia e la Spagna nella seconda metà del Settecento, Torino, Lattes, 1896.

6. M. Menéndez Pelayo, Ltalia y España en el siglo XVIII, en Estudios y Discursos de crítica histórica y literaria, Edición Nacional, IV, páginas 13-24.

Arturo Farinelli, La Spagna, il Conti e altri italiani del '700, en Italia e Spagna, Torino, Fratelli Bocca, 1929, II, págs. 287.327. 
cientos, Giovambattista Conti, que estuvo en España de 1769 a 1790; se refiere también ampliamente a los demás escritores y viajeros italianos que tuvieron contacto con la vida española, como Napoli Signorelli, Baretti y otros de menor importancia. Farinelli, por su parte, desahoga su farraginosa erudición para completar los datos sobre las relaciones de viajes y las impresiones recibidas recíprocamente por los visitantes de ambas naciones. A la vista de las largas notas repletas de datos eruditos, bien pudiera creerse que España era por entonces la "fiel sirvienta" de la cultura italiana. ${ }^{7}$ Pero lo único que puede resultar más convincente es el conocido e indiscutido influjo del melodrama, especialmente el de Metastasio. En cuanto a Menéndez Pelayo, al señalar sobriamente los puntos o referencias que podían haberse tenido en cuenta en un estudio global de relaciones, insinúa algunos posibles influjos, sobre todo en el campo de la lírica, aludiendo, creo que por primera vez, a las reminiscencias del Abate Parini en Jovellanos. No fue por tanto Morel-Fatio el primero que estableció esta relación literaria, según supone el autor del más reciente y sintético panorama comparativo, dedicado, como parte de un complejo estudio histórico, a la literatura italiana en la España de Carlos III. ${ }^{8}$

Pero mucho más abundantes que las aportaciones de conjunto, que son a su vez la suma de múltiples referencias dispersas, son las contribuciones parciales, que iremos teniendo en cuenta, limitadas a un autor, o a un aspecto, tendentes a establecer un influjo que sólo habrá sido verdaderamente eficaz cuando haya calado a fondo o condicionado corrientes de gusto o de cultura. De aquí, que el fenómeno aislado adquirirá únicamente sentido en función de la tota-

7. "In compenso, la Spagna, più dell'Italia estenuata di forze, appare, in arte e in poesia, in tutto il '700, la nostra fida ancella" (Farinelli, Italia e Spagna, ob. cit., II, págs. 312-13. 
lidad. Precisamente, el último estudio, centrado en la edición de una traducción inédita del italiano, empieza a dis. tribuirse en este año de 1966. Se trata de la versión hecha por el P. Isla del poema en octavas, hoy olvidado, Cicerone, de Gian Carlo Passeroni.' Una vez más estamos en presencia de un elemento cultural que puede tener su interés relativo para calibrar la técnica de la traducción -o más bien adaptación de unas formas y unos contenidos- en el P. Isla. Pero el peso en la cultura contemporánea fue nulo, sea por el escaso relieve de Passeroni, sea porque dicha traducción quedó inédita, sea incluso porque de los ciento un cantos de que consta el poema original, Isla sólo recrea o adapta una mínima parte, los 16 cantos ahora publicados. En general, la labor desarrollada por estos jesuitas expulsados en Italia tiene muy limitado alcance literario, como reconoce el P. Batllori, el mayor especialista en este campo, que acaba de reunir en un volumen la serie de trabajos de investigación dedicados a este tema a lo largo de 30 años. $^{10}$

En el ámbito más estricto del influjo italiano en España, los principales estudios se han concentrado en torno al teatro, es decir, la difusión en los escenarios españoles de las obras de Metastasio, Goldoni y Alfieri. Baste recordar ahora, sin perjuicio de discutir más adelante el alcance de dichas influencias, las aportaciones en lengua

8. Franco Meregalli, Storia delle relazioni letterarie tra Italia e Spagna. Parte III : 1700-1859 (appunti), Venezia, Librería Universitaria, 1962. El capítulo que nos interesa ocupa las páginas 86-106.

9. P. José Francisco de Isla, El Cicerón. Introducción, edición y notas de Giuseppe De Gennaro, Anejo XII del Boletín de la Real Academia Española, Madrid, 1965. El original se publicó en seis tomos entre 1755 y 1774. La traducción del primer tomo, y no completo, hecha por el P. Isla, parece que "debería datarse no después de 1774" (De Gennaro, pág. XIV).

10. "Esa literatura hispano-italiana tiene muy poco de creación $y$ macho de erudita: literatura muy diecioctiesca, en fin, cuando se llamaba titerato a los físicos y astrónomos, y la palabra literatura equivalía al sen. tido moderno del vocablo cultura" (Miguel Batlori, S. I., La cutrura his. pano-italiana de los jesaítas expulsos, Madrid, Gredos, 1966, pág. 17). 
italiana e inglesa de Stoudemire y Coester para el melodrama metastasiano, ${ }^{11}$ las de Rogers y Mariutti para la difusión de las comedias de Goldoni, ${ }^{12}$ y, en relación con la tragedia alfierana, los trabajos de Allison Peers y de Parducci. ${ }^{13}$

3.- $\mathrm{Si}$ me propongo restringir en su conjunto el alcance de la literatura italiana en el quehacer de los escritores españoles del siglo XVIII, es para dar el adecuado contrapeso a un campo de investigación y a una metodología que ha llegado indudablemente a unos resultados, pero no estrictamente literarios, sino eruditos y culturales. De aquí que, para evitar la parcialidad de unas consecuencias, trataré de adoptar un enfoque múltiple que vaya en lo formal de la lengua a la métrica, y en cuanto a los autores, de los literatos puros a los que no tienen este exclusivo carácter, de los poetas de siglos anteriores, ya con un valor histórico, a los rigurosamente contemporáneos y portadores de una problemática viva y actual.

El primer problema que me he planteado fue el de ver qué posibilidades materiales tenían nuestros escritores setecentistas de conocer o estudiar el italiano. Ante todo, por lo que se refiere a la lexicografía hispanoitaliana, muy pocas. Sólo dos diccionarios bilingües existían, el de Cristóbal de las Casas y el de Lorenzo Franciosini. Pero el primero, que se remonta a 1570 , no fue ya publicado después de

\footnotetext{
11. Sterling A. Stoudemire, Metastasio in Spain, en "Hispanic Review", IX (1941), págs. 184-191.

A. Coester, Influences of the lyric drama of Metastasio on the Spanish romantic movement, en "Hispanic Review", VI (1938), págs. 10-20.

12. P. P. Rogers, Goldoni in Spain, Oberlin-Ohio, The Academy Press, 1941. A. Mariutti de Sánchez Rivero, Fortuna di Goldoni in Spagna nel Settecento, en Studi goldoniani, Venezia, 1959, págs. 315-338.

13. E. Allison Peers, The vogue of Alfieri in Spain, en "Hispanic Re. view", VII (1939), págs. 122-140.

Amos Parducci, Traduzioni spagnole di tragedie alfieriane, en "Annali alfieriani”, I, (1942), págs. 31-152.
} 
1622. De sus 13 ediciones seguras, no obstante su autor fuese sevillano, únicamente dos son españolas (1570 y 1583); las restantes, todas venecianas. Por lo que se refiere al Vocabulario de Franciosini, que sustituyó al anterior desde su primera edición de Roma en 1620, ninguna de sus reimpresiones fue hecha en España, si bien cronológicamente siete de las cuales corresponden a lo largo del siglo XVIII. ${ }^{14}$ Sólo muy a fines del mismo siglo, 1793, demasiado tarde para ser utilizado, pertenece el tomo IV del Diccionario castellano del P. Esteban de Terreros, que comprende Los tres alfabetos francés, latino e italiano con las voces de ciencias y artes que les corresponden en la lengua castellana. Y como otro indicio más de las posibilidades que estoy reseñando, puedo recordar que en la biblioteca particular de Meléndez Valdés existía el Dizionario italiano, latino e francese, Lyon, 1770, del abate Annibale Antonioni. $^{15}$

En cuanto a las gramáticas para el estudio del italiano, sólo una bilingüe fue publicada en la España del siglo XVIII, de la que creo que nunca se ha hablado. Conozco, sin embargo, cuatro ediciones de la misma, todas de Madrid, 1772, 1779, 1789 y 1824. El autor de esta Nueva y completa Gramática Italiana explicada en español, según se deduce de la misma portada, era un abate, D. Pedro Tomasi, natural de Palestrina, muy cerca de la capital italiana, razón por la cual era conocido como "el romano". Pietro Tomasi fue quizás, en los últimos decenios del Setecientos, el centro de difusión de la lengua italiana en el ambiente madrileño, en el momento en que se siente la necesidad de las lenguas vivas y cuando el italiano es tenido en cuen-

14. Deduzco estos datos de Anna Maria Gallina, Contributi alla storia della lessicografia italo-spagnola del secoli XVI e XVII, Firenze Olschki, 1959. 15. Según Georges Demerson, Don Juan Meléndez Valdés et son temps (1754-1817), París, Librairie C. Klincksieck, 1962. 
ta asimismo en los planes de estudio que propugnan las nacientes Sociedades Económicas de Amigos del País. Por entonces también Jovellanos, en menos de veinte años (en. tre 1790 y 1809) preconiza por cuatro veces la importancia de las lenguas europeas modernas, sobre todo del francés y del inglés, pero sin olvidar en dos ocasiones al italiano, que interesa en una formación, no tanto profesional y técnica, como estrictamente histórico-literaria. ${ }^{16}$

4.- - Hasta hace muy poco, en 1962, no se podía calibrar con exactitud el conocimiento recíproco, entre España e Italia, del pensamiento ilustrado, perspectiva nueva, en este campo de estudios comparados, que abre un artículo de un historiador italiano, catedrático de la Universidad de Turín. ${ }^{7}$ De este estudio se deduce que así como los reformadores españoles, Uztáriz, Campomanes, Foronda, ejercieron influencia en Italia, las discusiones de los más calificados representantes de la ilustración italiana fueron bien conocidas en España, ya que se estimaba rica a Italia y con

16. En el Plan de educación de la Nobleza (1708). Gijón, 1915, atribuído a Jovellanos, se dice que, además de la lengua nativa y de la latina, se deben estudiar "la Francesa e Italiana, tan introducidas en la Sociedad y que tanto contribuyen para formar el gusto; y por la conexión que tienen su Historia y Literatura con nuestra Literatura y nnestra Historia" (págs. 157-58). Cuando más atclante se recomienda como gramáticis italituna "la del Abate Tomasino", este nombre hay que considerarlo una de tantas erratas de que está plagada esta edición; asimismo, el "Metastico" de líneas después tiene que ser Metastasio (págs. 224-25).

Lo que la lengua y la cultura italiana significaba en la formación cultural de la época, puede deducirse del siguiente curioso libro: Carta dirigida a un amigo, en que se le da razón de las Facultades, y Libros de que debe instruirse, no sólo un Poeta, sino qualqulera (sic) que aspire a una Erudición Universal. Su autor Don Manuel de Haedo y Espina. En Ma. drid... Año de 1769. Advierte que no se puede beber en las fuentes literarias "sin la tintura suficiente de las lenguas Griega pura y Griega actual, de la Hebrea, de la Francesa y de la Italiana" (pág. 62). Como elementos de estudio recomienda: "Para la Italiana el Arte de Franciosini o el de Veneroni; el tomo en folio de Monsieur Menagé; origen de la lengua Italiana, y el Diccionario de la Academia de la Crusca, que compone seis tomos en folio con un Compendio de einco en quarto, y que también se puede llamar Encyclopedia" (pág. 67).

17. Franco Venturi, Economisti e riformatori spagnoli e italiani del 700, en "Rivista Storica Italiana", LXXIV (1962), págs. 532-561. 
una vida económica más intensa. Los dos centros principales del "Illuminismo" italiano, Nápoles, con Genovesi y Filangieri, y Milán, con Cesare Beccaria, están presentes en la preocupación reformadora española a través de traducciones y comentarios.

Ahora bien, el único que de ellos ha tenido una repercusión literaria en España ha sido Beccaria, traducido en español por Juan Antonio de las Casas, a pesar de los obstáculos que se le opusieron, en 1774, es decir, diez años después de haber publicado anónimo su famoso tratado Dei delitti $e$ delle pene, base de la reforma penal y alegato apasionado contra la tortura y la pena de muerte. Son años de encendida polémica, y si en 1770 A. M. ${ }^{a}$ de Acevedo había declarado en un escrito en latín que la tortura era contraria a los derechos de la naturaleza, un canónigo de la catedral de Sevilla, D. Pedro de Castro, le impugnará de modo explícito en un tratado bárbaramente titulado Defensa de la tortura y leyes patrias que la establecieron. Ocurría esto en 1778 , un año después de haber prohibido la Inquisición española la traducción del libro de Beccaria.

El reflejo literario más acusado - anterior a la prohibición e incluso a la traducción española- de las tesis del penalista italiano se encuentran en El delincuente honrado de Jovellanos, y no sólo por sus significativas imprecaciones contra la tortura, sino también porque "de Beccaria procede la solución al problema de justicia concreta planteado en el Delincuente", o sea, "que la ley no debe castigar por igual al provocado y al provocador". ${ }^{18}$ El otro reflejo, mucho menos evidente, ha sido señalado en las Noches lúgubres de Cadalso por Edith F. Helman, ${ }^{19}$ por ciertas

18. José Caso González, El Delincuente honrado, drama sentimental, en "Archivum", XIV (1964), págs. 103-133. La cita en pág. 112.

19. José Cadalso, Noches lúgubres. Edición e introducción de Edith F. Helman, Santander-Madrid, Antonio Zúñiga, 1951, pág. 39. 
innegables aunque parciales analogías de actitud, y rechazado por Glendinning, que niega la huella de Beccaria en las obras de Cadalso. ${ }^{20}$ Muy significativo es, en todo caso, que la presencia de uno de los principales textos de la prosa prerromántica italiana haya sido notada o supuesta en las dos obras que, como ya he señalado en otro lugar, representan la cumbre de la prosa poética en el prerromanticismo español. ${ }^{21}$

Si de la reforma económica y de la legislación penal pasamos al aspecto religioso, al antagonismo polémico y efectivo entre reformadores y escolásticos o jansenistas y ultramontanos, también aparece en España el nombre de un italiano, Pietro Tamburini, y la repercusión de un imporlante acontecimiento del jansenismo italiano: el sínodo de Pistoya, en 1786. La reforma eclesiástica de este año en Toscana se debe al gran duque Leopoldo, que invitó al concilio a un grupo de teólogos dirigido por Tamburini. De la reacción española queda constancia en los Diarios de Jovellanos, que afirma tajantemente el 20 de marzo de 1795, que "toda la juventud salmantina es port-royalista, de la secta pistoyense", y que Tamburini, con otros jansenistas, "andan en manos de todos". El mismo declara, diez días después, que está leyendo, de Tamburini, la Vera idea della Santa Sede.

20. Cadalso, Noches lúgubres. Edición, prólogo y notas de Nigel Glendinning, Madrid, Clásicos Castellanos, 1961, págs. LIV.LV. En mi opinión, si puede dudarse de la coincidencia en opiniones, no es legítimo rechazar de plano - como hace Glendinning - la afirmación de la Helman de que "no cabe duda que Cadalso conocía esa obra" (pág. 39). Pero tampoco me parece probable, por las fechas, que su conocimiento haya llegado a $\mathrm{Ca}$ dalso a través de Conti, como contertulio de la Fonda de San Sebarstián.

21. J. Arce, Rococó, Op. cit., págs. 461-463. Se hace eco de la difusión del penalista italiano el P. Andrés en 179l: "¿Quién no conoce al famoso marqués Beccaria por su obra tal vez sobrado celebrada de los delitos y de las penas? Y no es ésta sola la obra que han producido su ingenio y su erudición." (Cartas familiares del abate D. Juan Andrés a su hermano D. Carlos Andrés, Madrid, Sancha, 1793, IV, pág. 201). 
5.-De los autores en una situación intermedia entre lo puramente literario y el plano ideológico-histórico, el más conocido en España fue, sin duda, L. A. Muratori. Los contactos entre Luzán y Muratori, ya indicados por Menéndez Pelayo, han recibido recientemente confirmación y precisión. ${ }^{22}$ Pero en la España del setecientos, Muratori no sólo importa como crítico literario, sino también, a juzgar por el número de sus traducciones, por sus obras de carácter religioso y moral. Así, por ejemplo, merecieron tres ediciones, en el curso de pocos años, títulos como La devoción arreglada del cristiano (1763, 1776 y 1783) o La Filosofía moral (1780, 1787 y 1790), mientras sólo podría citar una edición, entre otras, de Reflexiones sobre el buen gusto en las ciencias y en las artes (1782), de la Fuerza de la humana fantasía (1777) o de las Ventajas de la elocuencia popular (1780). Todas ellas fueron impresas en Madrid. En la Poética, de Luzán, donde Muratori aparece citado más de veinte veces, se recuerdan también, entre los italianos del siglo, a Gravina, Crescimbeni, Vico y Metastasio.

De Pietro Napoli-Signorelli, que figura entre los cultivadores de las letras asentados en España, a donde llegó poco después que Conti, en 1765, desde Nápoles, me interesa destacar, más que su labor de hispanista y de intermediario entre ambas culturas, ${ }^{23}$ un juicio suyo no expresado para la publicidad. Antes de abordar el aspecto estrictamente literario, que trato de enfocar no desligado de la general actividad cultural, deseo recordar una carta,

22. Véanse de Mario Puppo, Appunti sulla fortuna di L. A. Muratori in Spagna nel Settecento, en "Filología Moderna", III (1962), 7-8, págs. 137-140; y Fonti italiane settecentesche della "Poetica" di Luzán, en "Lettere Italiane", XIV (1962), 3, púgss. 249-268.

23. Cfr. A. Mariutti de Sánchez Rivero, Un ejemplo de intercambio cultural hispano-italiano en el siglo XVIII: Leandro Fernández de Mo. ratín y Pietro Napoli-Signorelli, en "Revista de la Universidad de Madrid" IX (1960), n. 35, págs. 763-808. 
escrita desde Madrid por Signorelli el 27 de julio de 1783 al marqués Albergati, en la que afirma:

"Gli Spagnuoli leggono poco i libri italiana, che non contengono panegirici della letteratura spagnuola; e gl'Italiani, che qui sono, per lo più attendono alla fortuna e non alla letteratura." ${ }^{24}$

Dos observaciones interesantes se deducen de la opinión de Signorelli: por una parte, que la serie de italianos que entonces vivían en España, en Madrid y Cádiz principalmente, estaban más atentos al buen logro de sus cuestiones personales o profesionales que al quehacer literario; por otra, la poca atención de los españoles a la literatura italiana. Los dos pueblos están certeramente retratados: la fusión constante del sentido práctico italiano con su fino instinto artístico; y la miopía de cierto tipo de cultura española atenta sólo a lo que exalta a su patria. Frente a los datos aislados de erudición, siempre multiplicables, o a contactos que pudieron haber sido ocasionales, me parece más significativo este tipo de afirmaciones de quien directamente vivió y captó la vida literaria del Madrid dieciochesco.

6.-Ya en el orden estricto de la literatura de creación, me parece indispensable distinguir previamente, entre los que han podido ejercer un peso efectivo, los autores italianos anteriores al siglo XVIII, de los que, en líneas generales, son contemporáneos. Creo que es una distinción importante, ya que una cosa es el escritor portador de una problemática viva o de unas formas innovadoras, y otra, muy distinta, el predominio ejcrcido por el que,

24. En Arturo Farinelli, Viajes por España y Poriugal, Roma, 1942, II, pág. 309. 
fuera del movedizo tiempo presente, está en la zona de lo universalmente reconocido, de lo indiscutible, de lo clásico.

De los grandes poetas italianos trecentistas o cuatrocentistas, sólo Petrarca puede ser tenido en cuenta. Dante merece una alusión, pero para señalar fundamentalmente el desierto de referencias, tanto en la crítica como en la poesía del siglo XVIII. No aparece ni mencionado en las principales poéticas de la época. Por los datos que tengo en mi poder, sólo a partir de 1770 empieza a nombrársele, pero como un vago dato de cultura literaria, no es un conocimiento directo. Quizás no sea ajeno a esta fecha el hecho de que Giovambattista Conti, en sus poesías italianas, fue un imitador de Dante, y estaba por entonces ya en contacto con los escritores madrileños. Curioso también que a esta década del 70 pertenece la traducción, ya citada, del Cicerone de Passeroni por el P. Isla. Y Passeroni, como en su poema lo demuestra, fue quizás el poeta italiano del siglo xviII que tuvo más en cuenta a Dante. De aquí que en El Cicerón recién publicado, de Isla, el nombre de Dante aparezca a menudo. Pero, al quedar inédita la traducción, no fue captado por la cultura de la época. Media docena de menciones, en parte debidas a los jesuítas expulsos en Italia, es lo que de Dante queda en la España del último trentenio del XVIII.

Petrarca es otra cosa. Petrarca es modelo indiscutido de la lírica amorosa y su prestigio no decae en ningún momento. Siempre se le cita entre los grandes ideales poéticos dignos de imitación o estudio. Nicolás F. de Moratín traduce, sin advertirlo, un soneto suyo. $\mathrm{Y}$ si queremos testimonios de la época, declaraciones explícitas, basten estas dos de Moratín hijo, de Leandro. En una de las notas que él mismo puso a sus poesías, concretamente en la de la oda que escribió en memoria de su padre, dice hablando de éste: "En sus composiciones amorosas imitó 
con maestría al Petrarca". ${ }^{25} \mathrm{Y}$ muy pocos años después, hallándose en Aviñón, escribe a Jovellanos una carta, el 13 de abril de 1787, para hablar - le explica- "de Petrarca y Laura, que es lo que usted quiere". Describe la ciudad, la catedral, cita versos del italiano, traduce en verso el epitafio en francés de su sepulcro construido en tiempos de Francisco I y "compuesto por el mismo Rey", visita la fuente de Valclusa, el valle, el risco "desnudo, hórrido", la caverna donde nace el Sorga, la casa del cura del pueblo con retratos antiguos de Petrarca y Laura ("el del poeta es idéntico al que yo tengo en Madrid, y usted conoce"), y termina lamentándose del "tiempo que han perdido muchos de los imitadores de Petrarca, así italianos como españoles", ya que no basla el numen poético y el estudio si la pasión de amor no es sincera y ha sido fingida. Pero lo más importante de todo es que, al referirse al amador de Laura, al "gran poeta", le añade a Jovellanos: "cuyos versos sabe usted de memoria". 26 Ahora bien, no obstante tan tajante afirmación, que demuestra que Petrarca sigue siendo un sustrato cultural en la poesía española del XVIII, sospecho que su conocimiento tuvo que ser en algunos casos de segunda mano. Y su presencia nada tiene de extraño porque, en fin de cuentas, el toscano era considerado un clásico, como Horacio o Virgilio.

7.-De los poetas del Cinquecento italiano, frente al mero reconocimiento de Ariosto como indiscutible autoridad literaria, destaca la persistencia de Torquato Tasso en citas, menciones y vivos recuerdos de episodios poéti.

25. B. A. E., II, pág. 614.

26. Obras póstumas de D. Leandro F. de Moratín, Madrid, Rivadeneyra, 1867, II, pág. 89. 
cos. Sin referirme a todos los que le tienen en cuenta -Feijoo, Cadalso, Forner, Jovellanos, L. F. de Moratín, Arriaza, Lista, etc.- bastará transcribir una significativa estrofa de una fábula de Iriarte:

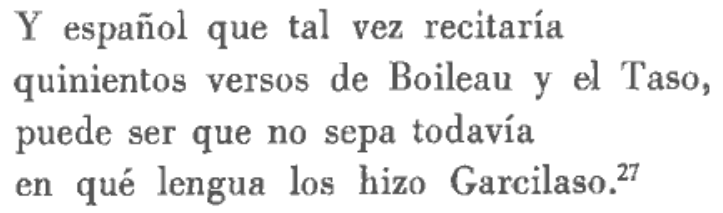

Hay dos Tassos, y en los dos sentidos deja su huella: el Tasso de la Gerusalemme Liberata y el Tasso juvenil del Aminta. Con el Aminta, traducido por D. Juan de Jáuregui a principios del siglo XVII, ha ocurrido un fenómeno curiosísimo que no creo tenga paralelo con ninguna otra obra: el de haber sido considerado y leído como un texto original, hasta tal punto que ha figurado siempre en las grandes colecciones y antologías de la poesía española. En la misma época de que tratamos, vuelve a reimprimirse en las colecciones de López de Sedano (1768) y de Estala (1786). Aquí sí podemos hablar de un influjo bien perceptible en una obra hoy casi olvidada, mezclado con algo tan nacional como el Quijote: en la comedia pastoral Las bodas de Camacho el Rico, de Meléndez Valdés. Pero fijémonos bien: el recuerdo de la lectura, que Jovellanos le había recomendado, pudo haberle llegado a Meléndez a través de la versión de Jáuregui.

Nada tiene de extraño esta preferencia por Tasso en el siglo XVIII, ya que en él se encuentran las dos máximas aspiraciones contrastantes de la poesía rococó e ilustrada: la idílico-musical y la heroica. Por eso se hace necesario aludir a la Gerusalemme, de la cual tenemos testimonios anecdóticos, como el que cuenta Leandro F. de Moratín en la Vida de su padre, con motivo de un en-

27. El té y la salvia, B. A. E., 63, pág. 14. 
cuentro entre D. Nicolás y el conde de Aranda. ${ }^{28} \mathrm{Y}$ mucho más significativo es lo que escribe el propio Leandro en su Viaje de Italia. ${ }^{29}$ Por mi parte, he insistido en otro lugar sobre la difusión alcanzada en la poesía española de fines del setecientos por un famoso verso de la Gerusalemme, "il rauco suon della tartarea tromba", que se convirtió en modelo arquetípico de exterior sonoridad. Sin embargo, su empleo reiterado por poetas miméticos se debe, en mi opinión, más que a la lectura de Tasso, al hecho de que Luzán lo pone como ejemplo de onomatopeya en su Poética, atribuyéndolo al oscuro Cristóbal de Mesa, que sí lo había copiado directamente del poeta italiano en el siglo XVII. ${ }^{30}$

A Petrarca y Tasso les sigue en orden de preferencias Gabriello Chiabrera, contemporáneo de Góngora, Lope y los Argensola. Se explica su simpatía en el XVIII por su papel de mediador en la doble línea de lo musical y lo heroico que va de Tasso a Metastasio. Es, pues, una vez más, el carácter mélico de la poesía italiana el motivo de atracción para los poetas españoles dieciochescos. A Chiabrera se le cita, pero no existen de él traducciones y no podría garantizar un influjo efectivo, salvo ciertas preocupaciones afines de tipo formal y métrico. $\mathrm{Y}$ no es el caso de referirse a los leves testimonios que nos constan de

28. B. A. E., II, pág. X.

29. "Dos muchachos, ciegos, cantaban alternativamente La Jerusalén, octava por octava, según el pasaje que se les pedía; ya la embajada de Argante, ya el conciliábulo de Plutón, ya la muerte de Clorinda, el palacio de Armida o el bosque encantado. ;Oh, Tasso inmortal, que a pesar de la envidia literaria, que llenó tu vida de amarguras, tu nombre, al cabo de dos siglos, vive famoso y superior a Ercilla, a Camoens, a Milton y Voltaire! Tus obras, aplaudidas de toda la Europa, son estudio digno de los sabios, y se cantan en las plazas públicas, donde el rudo vulgo las escucha con admiración y deleite." (Moratín, en Obras póstumas, op. cit., I, pág. 475.)

30. Joaquín Arce, Un verso de Tasso en la poesía española, en "Filología moderna", I (1961), 2, págs. 69-83. 
Marino o de Guarini, uno más, este último, en la línea melódica del Aminta tassesco.

Pasando de la poesía a la prosa nos encontramos ante un hecho a un tiempo curioso y desconcertante: la obra de mayor difusión, la más reeditada en la España del XVIII, es una traducción, hecha por D. Juan Bartolomé, de la — ¡atención al título!-- Historia de la vida, hechos y astucias sutilísimas del rústico Bertoldo, la de Bertoldino su hijo y la de Cacaseno su nieto, que, a partir de su primera edición en 1745 , se reimprime en $1769,1781,1788$, 1797 y, todavía en el siglo siguiente, en 1816, 1817, 1821, 1840, 1845, 1849, 1851, etc. ${ }^{31}$ La obra original, publicada en 1606, de Giulio Cesare Croce, es una muestra en Italia de la novelística barroca de tipo popular, pero su divulgación en España nada tiene que ver con el respeto sentido hacia los valores permanentes de la literatura italiana.

8.-Llegamos así a los autores italianos del siglo XVIII, a los que pudieron condicionar nuevos gustos o nuevas preferencias. De la poesía de la Arcadia, la que primero llegó fue la solemne y vacua de Vincenzo Filicaia y Carlo Innocenzo Frugoni. Al menos, son los dos únicos poetas contemporáneos que nos constan leídos, según testimonio de Moratín, en la tertulia de la Fonda de San Sebastián. El mismo Moratín traduce aisladamente un sonetillo dialogado de Paolo Rolli. Y también, entre los autores de segunda fila, debe recordarse la simpatía que Jovellanos sintió por Saverio Bettinelli, más por sus tragedias que por su obra en prosa. ${ }^{32}$

31. Según el Esbozo de una bibliografía española de traducciones de novelas (1800-1850), intentado por José F. Montesinos en Introducción a una historia de la novela en España, en el siglo XIX, Valencia Castalia 1955.

32. Ya tratado por José Caso González, Teorías métricas de Jovellanos en dos cartas inéditas, en "Boletín del Instituto de Estudios Asturianos" 
Pero lo verdaderamente importante es ver, por fin, qué huella han dejado las grandes figuras del Settecento, líricos como Metastasio y Parini, dramaturgos como el mismo Metastasio, Goldoni y Alfieri.

La larga vida de Pietro Metastasio (1698-1782), su elección como poeta cesáreo en la corte de Viena, su fama indiscutida en toda Europa, crea para la cultura española un capítulo de influjos asombrosos, que más pertenecen a la historia de la moda y de las costumbres que al arte propiamente dicho. Metastasio inunda la escena europea, y por consecuencia la española, con sus dramas con "melos", con música, y es en esta línea de la poesía mélica como debe ser efectivamente valorada su influencia. Ahora sí estamos en presencia de un autor que se impone, que orienta modos de sentir, que sacia la sensibilidad mórbida y lánguida de toda una época. Y ello se logra, naturalmente, gracias al teatro, a la representación que tiene lugar ante la presencia física del espectador.

Pero hay también un Metastasio lírico, el afortunado creador de las canzonette, que también fueron divulgadas en España. Dos, sobre todo, que siguen apareciendo en todas las antologías, alcanzaron una inusitada popularidad: La libertà ("Grazie agl'inganni tuoi") y La Partenza ("Ecco quel fiero istante"). Aparte reminiscencias parciales en otros poetas - como en Jovellanos, señaladas por Fucilla ${ }^{33}$ es curioso el hecho de que tres de los más significativos poetas de finales del siglo, Meléndez, Cienfuegos y Arriaza, hayan traducido o imitado muy de cerca las dos canzonette. Es más, Vargas Ponce, que creo

\footnotetext{
núm. 39, 1960, págs. 125-154; y por J. Arce, Traductores asturianos de poesía italiana en los siglos XVIII y XIX, en "Archivum", XII (1963), págs. 527-547.

33. Joseph G. Fucilla, Poesias Líricas de Metastasio en la España del siglo XVIII y la octavilla italiana, en Relaciones hispanoilalianas, Madrid, Anejo LIX de la Revista de Filología Española, 1953, págs. 202-214.
} 
fue el primero en comparar, en 1793, el texto de Melénde\% con el original italiano, dice al referirse a La Libertà: "la famosísima canción del Metastasio, que sabe de memoria todo hombre sensible". ${ }^{34} \mathrm{Y}$ bien sabemos que el ideal humano a fines del XVIII es el hombre sensible. Pero una prueba más convincente de la popularidad de estas versiones, que alcanza a la sociología y a los hábitos lingüísticos del pueblo, nos la da precisamente Pérez Galdós en la novela que más profundamente aborda la transformación social y económica del Madrid de 1870. En un diálogo de separación entre Juanito Santa Cruz y Fortunata, ésta le dice: "Ya llegó el instante fiero - Sil. via, de la despedida. Déjame aquí. Adiós, hijo de mi vida. Acuérdate de mí..." ${ }^{35} \mathrm{O}$ sea, en una novela realista, de 1887-88, todavía se injertan, como pertenecientes a la espontaneidad lingüística de los personajes, en situacio. nes sentimentales equivalentes, versos que corresponden a la traducción por Arriaza de La Partenza.

9.--Pero lo que hace de Metastasio la última figura verdaderamente universal de la literatura italiana fue el melodrama. Las representaciones y las traducciones, con breves intervalos de descanso, se suceden durante más de sesenta años. El número de publicaciones españolas de melodramas supera el medio centenar y algunos de ellos se reimprimieron hasta cuatro veces. Desde 1738, en que se publican Demofoonte, Artajerjes y Alejandro en las Ir dias, empieza también la costumbre de hacer ediciones bilingües, con el texto traducido a la derecha y el original italiano a la izquierda. Unas bodas en la corte, un bautizo,

34. Declamación, op. cit., pág. $125 \mathrm{n}$.

35. Benito Pérez Galdós, Fortunata y Jacinta, Madrid, Hernando, 1944,

t. III, pég. 387 . 
una fiesta solemne, eran la ocasión y el pretexto para que en el teatro del Buen Retiro se solemnizara el acto con la representación de un melodrama metastasiano. De cómo eran acogidos y cómo eran anunciados da idea este suelto aparecido en la "Gaceta de Madrid" el 4 de octubre de 1791:

"El Demofoonte del Abate Pedro Metastasio, traducido al Castellano, y representado por la Compañía de Eusebio Rivera en el Coliseo del Príncipe el día 27 de setiembre de este año, con el título del Inocente usurpador. No necesita el nombre de Metastasio de ser recomendado: bien conocido es su mérito en la república literaria: el traductor ha procurado copiar en el mismo verso las bellezas del original con toda la fidelidad posible, imitando la rapidez, fuerza, precisión y viveza del diálogo; y el público ha recibido con aplauso la copia de uno de los quadros más bellos y tiernos de lan insigne autor."

Nadie le regatea elogios. En todos los tratados de teoría o crítica literaria se le pone siempre por modelo. Quien pretende poner reparos a la lengua o a la técnica del melodrama, hará la excepción - como Luzán, como García de la Huerta-, con Metastasio. Conocidas son sus relaciones epistolares con Iriarte y cómo éste se envanecía de los elogios que el italiano le había prodigado. Incluso PII el ámbito recoleto de la correspondencia parlicular se expresará abierta admiración. Escribe Meléndez a Jovellanos en 1777: "Aora estoy con la Theodicea de M. Leibnitz y con el Metastasio que me han traído, y estoy envelesado con ellos, que es cuanto puedo encarecer el gusto que me dan". ${ }^{36}$ Y en carta desde Viena, en 1781, Viera y Clavijo no puede dejar de consignar: "Nos ha visitado y he-

36. Publicada en la "Revue Hispanique", IV (1897), pág. 310. 
mos visitado al inmortal poeta Cesáreo Pedro Metastasio". ${ }^{37}$

El verdadero predominio, la tiránica presencia de Metastasio en la escena y en la imprenta española corresponde a los momentos iniciales y finales de la segunda mitad del siglo XVIII, es decir, al ventenio 1750-1769 y a la década 1790-1799. En esta intermitencia influyó sin duda la prohibición temporal de representaciones de ópera de 1777 , pero se adapta perfectamente a dos diferenles etapas del gusto: por una parte, a la poesía de la Ilustración, que sólo aparece después de mediado el siglo y en la que confluyen distintas corrientes, incluso la rococometastasiana; por otra, la nueva interpretación que se hace metastasiana; por otra, a la nueva interpretación que se hace del sentimentalismo mórbido de Metastasio, que se incorpora a la sensibilidad prerromántica de fines del Setecientos.

10.-La posibilidad de la lectura metastasiana en registros diversos, ha dado lugar a una curiosa paradoja en la historia de la métrica española: la estrofa típica del rococó setecentista es habitualmente considerada en nuestra poesía como una de las formas estróficas características del romanticismo. Me refiero a la que se conoce hoy como octavilla italiana, pero que no se llamaba así en la época de que estamos tratando. La vinculación, sin embargo, es indiscutible. Iriarte la usará precisamente en una letra para un dúo italiano, imitada de Metastasio, que es, en efecto, una síntesis de La Partenza. También el jesuita montañés A. Fernández Palazuelos intercalará la misma estrofa en una traducción de los Cánticos de Salomón, en los que

37. Cartas familiares escritas por don José Viera y Clavijo a varias personas esclarecidas, por sus dignidades, clase, empleos, literatura o buen carácter de amistad y virlud, Santa Cruz de Tenerife, s. a. 
precisa: "Versión poética en metro metastasiano". El poeta italiano emplea esta combinación estrófica con rimas en agudo en los versos final y medial (es esto lo característico y no el número de versos, que varía, ni la medida de los mismos) no sólo en las citadas e imitadas canzonette, sino también en las arietas de sus melodramas. Ya Jovellanos lo había expresado claramente: "Las arietas, que hemos imitado de los italianos modernos, quieren también este género de verso corto, bien sean de ocho, siete, seis y aun cinco sílabas, con la particularidad solamente de haberse de rimar una copla en final aguda". ${ }^{36}$

Es en las últimas décadas del Setecientos cuando esta modalidad métrica se extiende a un notable número de poelas, Iriarte, Meléndez, Noroña, Arriaza, Fernández Palazuelos, L. F. de Moratín, Arjona, Cienfuegos, Sánchez. Barbero y todavía, en pleno siglo XIX, a través de la mediación de Alberto Lista, Llega a los más grandes líricos románticos, Espronceda, Zorrilla y Duque de Rivas. E iilcluso hay antecedentes anteriores, ya que la misma combinación aparece en forma aislada en Moratín padre y hasta en Eugenio Gerardo Lobo, para no hacer mención del peruano P. Peralta Barnuevo (1695-1743), que la utilizo en algunos cantables de sus obras de teatro, pero que no creo haya tenido ningún peso en nuestra Península. ${ }^{39}$ Sólo, pues, la rutina crítica ha podido considerar estrofa típicamente romántica la que está presente, sobre todo, en el Prerromanticismo español, después del uso consciente, de estímulo metastasiano, que hace de ella Meléndez Valdés. Que la vía de acceso directa hayan sido las ariette del melodrama, como quiere Coester, o las canzonette, según

38. Lecciones de Poética, B. A. F., 46, págs. 140-141.

39. T. Navarro Tomás, Métrica española, Reseña histórica y des. criptiva, Syracuse, New York, 1956. 
pretende Fucilla, ${ }^{40}$ me parece cuestión, no sólo insignificante, sino discutible, ya que no habría que descuidar completamente los antecedentes mencionados.

En relación con esta distribución estrófica, mezclando, no sólo los agudos con los graves, sino también los esdrújulos, y adoptando una combinación más compleja con contenidos más serios y menor musicalidad superficial y externa, está la estrofa que incorpora a nuestra lírica Leandro F. de Moratín, la duodécima, utilizada en la elegía $A$ la muerte de don José Antonio Conde. Pero, dada la fecha (1820), nos alejamos de nuestro campo de estudio y podemos considerarla ya de derivación manzoniana. ${ }^{41}$

Estos datos, junto con las variaciones que se dan en la misma época a la estrofa sáfico-adónica — que no estudio aquí porque no las considero de origen italiano- hacen inadecuada e incompleta la afirmación de Milá y Fontanals, referida a la métrica del XVIII: "En el siglo pasado apenas se imaginó otra innovación que la acertada de aplicar el asonante al endecasílabo". ${ }^{42}$

11.-En relación con el influjo ejercido en la frívola vida del Setecientos por los melodramas de Metastasio se halla un problema de alcance lingüístico: el problema de las traducciones. Téngase presente que muchas de las palabras o expresiones italianas que se han incorporado al español, utilizadas frecuentemente con intención caricaturesca, han penetrado a través de la ópera. El mismo gé-

40. A. Coester, Influences, op. cit, Y J. G. Fucilla, Poesias líricas de Metastasio, ob. cit.

41. Véase la primera estrofa: "jTe vas, mi dulce amigo, / la luz huyendo al dia! / i $\mathrm{Te}$ vas, y no coninigo! / i $\mathrm{Y}$ de la tumba fria / en ol estrecho límite, / mudo tu cuerpo esta! / Y a mí, que débil siento / el pégo de los años, / y al cielo me lamento / de ingratitud y engaños, / para llorarte imísero! / large vivir me da." (B. A. En, II, pág. 592).

42. M. Milá y Fontanals, Obras completas, Barcelona, ed. Menéndez Pelayo, 1888-1896, I, pág. 409. 
nero chico parodió muchas veces la aparatosidad de situaciones y sentimientos del espectáculo lírico.

El melodrama metastasiano no sólo es elemento que debe considerarse en la historia de las costumbres, sino que produjo deletéreos efectos para la lengua española a juzgar por la reacción de los puristas y lingüistas del siglo XVIII. Entiéndase bien que el mal es atribuido a todo género de traducciones. Pero la abundancia, persistencia y apresuramiento con que tendrían que ser hechas las versiones melodramáticas para publicarlas solas o en ediciones bilingües, hace de estos libretos el principal punto de mira de los ataques. ${ }^{43}$

Para examinar este estado de cosas, de lo general a lo particular, vamos a fijarnos fundamentalmente en dos tes. timonios contemporáneos, de 1789 y 1793, pertenecientes a dos escritores preocupados por la realidad cultural del país. Sempere y Guarinos, en su bibliografía correspondiente a la época de Carlos III, después de hacer una larga reseña alfabética de los literatos y hombres de ciencia, dice al final que debiera haber añadido un capítulo de Traductores, necesario para el conocimiento exacto del estado de la literatura española. Les reconoce como ventaja positiva haberla enriquecido de ideas y purgado de ciertos vicios de expresión, desde la sutileza a las metáforas. Pero cree que han traicionado su intrínseca peculiaridad: "La mayor parte de los traductores de lenguas vulgares han afeado nuestro idioma con voces y frases nuevas, y con cierta languidez muy agena del carácter y genio de los

43.' "Estamos viendo en nuestros días salir traducciones infinitas muy miserables de las Operas del Metastasio, de Tragedias Francesas, etc., en todas las quales (a excepción de dos o tres) se advierte el mal gusto y poca habilidad de nuestros modernos traductores" (D. Ramón Fernández, seudónimo de Pedro Estala, Colección de poetas españoles, t. VI, Madrid, Imprenta Real, 1786, pág. 15). 
Españoles". ${ }^{44}$ La opinión me parece muy interesante porque nos da la clave de esa prosa llena de blandas cadencias que me parece característica, según he expuesto en otras ocasiones, de la literatura prerromántica y que Sempere señala como de claro influjo extranjero. Y, evidentemente, la musicalidad y morbidez del verso metastasiano han sido máximos responsables del reblandecimiento y afeminamiento de mucha poesía de entonces.

La otra opinión, de Vargas Ponce, es mucho más explícita y casi obsesiva a juzgar por las veces que insiste sobre esta cuestión en la misma obra. No escatima insultos a los traductores ni advertencias a los jóvenes: "Así holláis el idioma, Traductores ignorantes, así le habéis obscurecido y afeado, y es obra vuestra la deplorable deformidad en que yace". "Incauta juventud..., desprecia y abandona la deshecha lluvia de traducciones, que hoy inundan la Nación". Un poco más adelante centrará ya el principal objeto de sus acusaciones: "También, y de otro nuevo modo, la Opera Italiana concurre ahora en la Corte al lamentable. destrozo que sindicamos. Las pésimas traducciones de sus Melodramas, hechas con el mayor desaliño y por manos; mercenarias e indoctas, acrecen la dolencia común y el desentono del lenguaje; por lo qual, no sólo el áspero y monótono Francés, sino el Italiano vario y dulce, el Italiano tan igual con nuestro idioma, tan uno por tantos respetos, y entre quienes están indecisas las ventajas, multiplica hoy los motivos de nuestros sinsabores". Así nos encontramos, en las óperas representadas en los Caños del Peral, al "piacere italiano vuelto en regocijo español". A pesar de esta conclusión sarcástica, el autor se siente en la obligación de hacer algunas excepciones, y señala los nombres

\footnotetext{
44. Juan Sempere y Guarinos, Ensayo de una biblioteca española de los mejores escritores del reynado de Carlos III, Madrid, Imprenta Real, 1785.89 , t. VI, pág. 230.
} 
de Azara, Iriarte, Clavijo y, sobre todo, a la Marquesa de la Espeja - "estudiosa y delicada", que domina su lengua a pesar de ser "Dama muy joven y educada fuera de su patria- por su traducción del compendio de Filosofía Moral (1785), de F. M. Zanotti. ${ }^{45}$

Eran necesarias estas referencias para poder comprender cómo la presencia abrumadora de melodramas metaslasianos representados y traducidos pudo significar hasta un peligro para la lengua española, un aspecto más de un campo de estudio que con mayor derecho pertenece a la sociología literaria.

12.- La renovación teatral llevada a cabo en la Italia del siglo XVIII, en tan distinto sentido, por Metastasio, Goldoni y Alfieri, obliga a abordar seguidamente el problema de su influencia. Anticipemos inmediatamente que tiene un carácter completamente diverso en los tres autores y que por amplitud y eficacia no pueden los dos últimos parangonarse al primero.

Me atrevería a decir que Goldoni fue mucho más traducido que valorado, al menos en su verdadero significado literario. Hay un Goldoni, hoy mucho más olvidado, que es el Goldoni de los melodramas jocosos. El fue, efectivamente, uno de los primeros que compusieron obras notables para su tiempo, en el campo del melodrama, con mezcla de personajes o situaciones cómicas. $\mathrm{Y}$ estos dramas jocosos, ya con música o transformados en zarzuelas, en español, italiano o en ediciones bilingües, en verso o en prosa, son la vía por la que penetra en España el comediógrafo veneciano. Su postura inicial, por tanto, coincide. en menor grado naturalmente, y en tonos y ambientes más

45. J. Vargas Ponce, Declamación, op. cit., págs. 43, 44, 45, 51-52, 180.181 y 202. 
populares, con la de Metastasio. Realmente fue muy representado, ya que se tiene noticia de, al menos, unos 30 dramas jocosos y unas 40 comedias que pasaron por la escena española, aunque adviértase que se difundió más en Bar. celona que en Madrid. Y no falta tampoco, en el caso de Goldoni, el detalle anecdótico de su presencia en las costumbres de la época. En efecto, si durante algún tiempo se habló de modas y peinados a la Cecchina, fue como consecuencia de haberse representado La buena hija, es decir, Cecchina, la buona figliuola, entre 1762 y $1772 .{ }^{46}$ $\mathrm{Si}$ es a partir de 1750 cuando empiezan a darse a conocer los dramas musicales, la comedia propiamente dicha sólo triunfa desde 1770 hasta finalizar el siglo, aunque la primera comedia representada, La esposa persiana, se remonta a 1765.

En el caso de Goldoni, tras de tratar en general de su difusión en España, se hace necesario plantearse el problema de sus relaciones más directas con Moratín y Ramón de la Cruz. Es bien conocida la visita que Leandro F. de Moratín hizo a su "buen Goldoni", hallándose éste en París, en $1787 .{ }^{47}$ Los veintisiete años del primero frente a los ochenta del segundo son indicio claro de que la visita tiene el carácter de un público reconocimiento, pero es el reconocimiento a lo ya definitivamente consagrado, el que se concede a la antigüedad venerable. Que Moratín conocía bien la obra de Goldoni, que le estimaba y admiraba, es indudable. Que en su concepción general de la comedia haya también tenido su parte el veneciano, parece bien admisible. Pero son dos autores de temple muy distinto. Piénsese simplemente en la exuberancia desbordante del italiano, con sus 250 obras teatrales como mínimo, en su

46. Para todos estos datos, téngase en cuenta a Mariutti, Fortuna di Goldoni, op. cit.

47. Obras póstumas, op. cit., II, págs. 94-95. 
interpretación localista y pintoresca de la vida, y en la timidez y contención del español, en su fino sentido del límite que le lleva a escribir tan sólo cinco comedias originales (más tres traducciones de Shakespeare y Molière), de acción sobria y escasos personajes, que hablan para una sociedad más bien culta, indiferenciada en cuanto a características lingüísticas o ambientales. En la entrevista mencionada, al referir Moralín a Goldoni qué obras de éste se representaban en Madrid, alude muy significativamente a las "producciones estimables de su demasiado abundante vena". Y ante esta clara toma de posición, que puede ser reforzada con otras citas del mismo carácter, ${ }^{48}$ una conclusión es evidente: nadie ha podido aportar pruebas de un electivo influjo de Goldoni sobre Moralín.

Ramón de la Cruz plantea un problema diverso, ya que gracias a él, a sus traducciones y adaptaciones de los dramas jocosos goldonianos, se difundieron éstos en Éspaña. Es más, se trata sin duda del más importante traductor de Goldoni en la España del siglo XVIII. Pero lo que no ha podido ser documentado es que haya elementos en el teatro de Ramón de la Cruz derivados del italiano, pues si es innegable a veces cierta analogía, más parece coincidencia de dos parábolas (atenuación de un realismo tradicional en el español, renovación realista y educativa en el italiano) que influjo. ${ }^{49} \mathrm{Nada}$ de lo cual obsta naturalmente para que, durante la década del 60 , en cuanto a las ediciones, y sobre todo durante las del 70 y 80 , por lo que se refiere a las traducciones, el teatro goldoniano fuera acogido con gusto y aplauso por el público español.

48. Carlo Consiglio, Moratín y Goldoni, en "Revista de Filología Española", XXVI (1942), págs. 1.14.

49. ' Según Franco Meregaili, Goldoni e Ramón de la Cruz, en Studi goldoniani, Venezia, 19.59, págs. 795-800. 
13.-Más importancia, más peso efectivo ha tenido en la cultura literaria española el teatro de Vittorio Alfieri. Sin embargo, aquí le dedicaremos muy poco espacio. El motivo es claro: tanto las tragedias traducidas (nueve, desde 1806 a 1857) - -y hasta algunos "arreglos" (el Saúl de F. Sánchez Barbero es de 1805) - , como las representadas (recuérdese el Bruto primo, llevado a la escena en la Cádiz de 1812 con el significativo título de Roma libre), pertenecen de lleno al siglo XIX, es decir, son posteriores a la muerte del autor (1803). Lo mismo habría que decir de algunos juicios y críticas muy significativas y de la serie de obras dramáticas que pueden aducirse como de muy probable derivación alfieriana, muy necesitadas por otra parte de un estudio a fondo.

Si indiscutiblemente la fortuna de Alfieri en España pertenece al Ochocientos, los primeros datos sobre su conocimiento se encuentran ya en la última década, o muy poco antes, del siglo que estudiamos. Los testimonios más antiguos que pueden aducirse pertenecen a dos jesuítas expulsos, a Esteban de Arteaga y a Juan de Andrés. Pero a nuestros fines no tienen excesivo significado. Del P. Arteaga, aparte de menciones sin importancia, deben recordarse cinco cartas en que hace juicios explícitos en torno a las obras del trágico italiano, escritas entre 1783 y 1792. Pero tres de las cartas han quedado inéditas y otra no se publicó hasta 1803. Todas, por otra parte, están en italiano. Su difusión habrá sido por tanto mínima o nula y sólo, para el XVIII, puede tener significado aludir a la dirigida a monseñor Antonio Gordoqui, que ya fue publicada en 1792 y que se refiere a una tragedia de tema español, al Filippo. Su opinión es más bien negativa, ya que le censura, en cuan. to a la lengua y a la técnica, lo que fue frecuente objetarle 
por entonces, la dureza del estilo, el abuso de soliloquios y la falta de ternura. ${ }^{50}$

La obra fundamental del P. Andrés, Origen, progresos y estado actual de toda la literatura, empezó a ser publicada en la traducción española a partir de 1784. En el teatro alfieriano señala preferentemente la reducción de personas y cosas a lo esencial, lo cual arrastra a la oscuridad de la acción y a que las pasiones no siempre sean llevadas gradualmente. Y junto con su incompatibilidad con las escenas atroces, el odio al tirano, las venganzas y suicidios, insiste en la frecuencia de monólogos y en el estilo duro e inarmónico. ${ }^{51}$

De autores españoles bien caracterizados que den un poco de luz al alfierismo de los últimos años del siglo XVIII, no pueden olvidarse Jovellanos ni Leandro F. de Moratín. Del primero sólo conservamos este dato escueto pero muy significativo: el día 6 de setiembre de 1794, por la época en que estaba leyendo las Confesiones de Rousseau, anota en sus Diarios que ha escrito pidiendo "el Teatro de Alfieri". Dedúzcase, pues, en qué tardía fecha un avanzado de la cultura como era Jovellanos pudo entrar en contacto con el trágico italiano. De Moratín, que ya está a caballo entre los dos siglos, merece la pena destacar algunos adjetivos que reflejan bien su reacción espontánea, bien sea cuando nombra al "terrible Alfieri" como cuando declara: "su estilo ha sido muy censurado de duro y gótico" ${ }^{52} \mathrm{El}$ calificativo gótico es todo un símbolo de época.

50. Para las cartas de Arteaga, véase A. Parducci, Traduzioni spagnole, op. cit.

51. Giuseppe Carlo Rossi, Metastasio, Guldunh, Alfieri e $i$ gesutit spagnoli in latia, en "Aunali dell'Tstituto Universitario Orientale". VI (1964), 1, págs. 71-116, Si en el trabajo mencionado de Parducci no se tiene en cuenta al P. Andrís, Rossi no considera algunas cartas del P. Arteaga al hacer caso omiso del artículo de Parducci.

52. B. A. E., II, pág. 323; y Obras póstumas, cit., I, pág. 478. Moratín insiste en este último lugar en la simplificación de la tragedia operada 
14. -El poeta central de la Ilustración italiana es Giuseppe Parini (1729-1799), que bien pudiera ser la clave de comprobación de un influjo efectivo mediante una poesía portadora de los ideales del siglo. Es tema no estudiado todavía, que sólo ha sido insinuado, sobre el que tengo infinidad de datos que permiten afrontarlo marginalmente. Quiero decir con ello que una huella directa, debida a un conocimiento innegable de los textos parinianos, no puede aducirse como clara prueba en la poesía setecentista, al menos en los nombres que si suelen repetir. Menéndez Pelayo se refirió varias veces al poeta italiano en relación con cierto tipo de sátira antinobiliaria. Pero, aparte el hecho de que algunos de estos autores - Eugenio de Tapia, José J. de Mora - pertenecen ya al XIX, yo creo ver en ellos derivaciones de Jovellanos más que de Parini. En todo caso es a Menéndez Pelayo a quien corresponde el honor de haber señalado, creo que por primera vez, las posibilidades de una relación con Parini en algunas poesías del siglo XVIII. Los nombres aportados por el crítico santanderino son fundamentalmente dos: Jovellanos y Moratín hijo. Y creo que merece la pena destacar que, aunque un tanto vagamente, las fechas de los escritos que contienen esas afirmaciones pertenecen a los años 1877,1890 y 1896 , es decir, son anteriores a la edición de la segunda sátira de Jovellanos, por Morel-Fatio, que pasa por ser el primero que apuntó a dicha relación. ${ }^{53}$

La razón aducida, sin embargo, por el crítico santanderino en la citada reseña al libro de Cian, no me parece

por Alfieri y en su prescindir de personajes inútiles, que impiden que sus obras tengan variedad y movimiento; pero le reconoce grandes ideas, máximas sublimes, llegando a la conclusión de que merece "el primer lugar entre los modernos".

53. M. Menéndez Pelayo, Estudios y Discursos, op. cit., IV, pág. 23; V, pág. 344, y VI, pág. 34. Alfred Morel-Fatio, La satire de Jovellanos contre la mauvaise éducation de la noblesse, Bordeaux, 1899. 
convincente: "donde verdaderamente es pasmosa, y no parece casual, la semejanza con el poema del Giorno, tanto en el espíritu como en los procedimientos artísticos (mezcla de indignación e ironía), es en la segunda sátira de Jovellanos..." Unos años después, Morel-Fatio estimaba que Jovellanos "a dû prendre connaissance" del Mattino y Mezzogiorno, únicas partes publicadas hasta entonces, y que la "peinture du giovin signore milanais n'a pas été sans influence sur la composition de la seconde satire à Arnesto". Pero objetaba con razón que entre la expresión de uno y otro "il y a un abîme". Curioso además que los únicos versos del italiano citados por el crítico francés en las notas para establecer una semejanza, la descripción del escudo, pertenecen al Vespro, la tercera parte del Giorno, que fue publicada póstuma en 1801 .

Por mi parte, he comparado en otra ocasión un temit poético en el que coinciden Parini y Jovellanos, la descrip. ción del carruaje y el estruendo de sus ruedas. Pero destacaba entonces, más que algunas aproximaciones, las evidentes diferencias de actitud y de sensibilidad, la reacción del asturiano "ante lo inmediato y concreto, sin parangón en la contemporánea poesía italiana", y su atención a lo "pintorescamente popular" que le lleva a poner "el acento poético en los elementos estridentes e incómodos de los coches de viajeros sobre los carruajes de lujo personales..."

La sátira de Jovellanos es de 1787 y ésta sería, en el caso muy hipotético de que hubiera conocido el Giorno, la fecha más antigua de una derivación pariniana en la poesía española. Lo cierto es que no existe en toda la obra de Jovellanos ni en ninguno de sus contemporáneos, a no ser los que visitan Italia en los años finales del siglo, ningun:

54. J. Arce, Jovellanos y la sensibilidad prerromántica, en "Boletín de la Biblioteca de Menéndez Pelayo", XXXVI (1960), pégs. 170-171. 
referencia a Parini. Ni existe, en cuanto a la técnica satirica, ese procedimiento pariniano de antiepopeya o de epopeya de lo inútil y vacío, de exaltación refinadamente retórica de la ociosidad. La sabiduría estilística y rítmica de Parini se complace en un alarde de recursos expresivos para cantar solemnemente la inanidad, los actos, objetos y ceremonias que consumen detalladamente la hueca jornada del noble milanés. La poesía española de la época utiliza o una ironía más espontánea e ingenua o una sátira mordaz, directa, de tono realista. No, no es en el procedimiento arlístico donde puede buscarse la huella pariniana, sino en los elementos y características de la vida del noble.

15. - En este sentido, creo poder aportar un testimonio nunca recordado a este respecto, de quien parece pretender, en muy pocas líneas, hacer el resumen del contenido del Giorno. Es Cadalso, en la XLI de las Cartas Marruecas. Recuérdese, al principio del Mattino, el despertar del señor, los "valetti gentili" que acuden, el "ben pettinato... damigello", la manía orientalizante de los objetos y vestidos, la "bevanda... da Moca", el sastre con título de Monsieur, el maestro de danza, el de francés, el volumen de piel y oro gracias al encuadernador "Batavo o Franco"; y de nuevo, en el Mezzogiorno, las bandejas ornadas por el "Sàssone industre", el café que ahuma porque es "bollente bevanda", tras recordar por inciso, al final de la primera parte, Ia asistencia al teatro para el espectáculo musical. Reléase todo ello, concentrado, resumido, en la prosa de Cadalso:

"Despiértanle [al poderoso de este siglo] dos ayudas de cámara primorosamente peinados y vestidos; toma café de Moca exquisito en taza traída de la China por Londres; pónese una camisa finísima de Holanda, luego una bata de mucho gusto tejida en León de Francia; lee un libro encuadernado en París; 
viste a la dirección de un sastre y peluquero franceses; sale con un coche, que se ha pintado donde el libro se encuadernó; va a comer en vajilla labrada en París o Londres las viandas calientes, y en platos de Sajonia o de China las frutas y dulces; paga a un maestro de música, y otro de baile, ambos extranjeros; asiste a una ópera italiana, bien o mal representada, o a una tragedia francesa, bien o mal traducida..." 55

Este es el cuadro del lujo moderno y extranjero que Ca* dalso contrapone al nacional antiguo. Se limita, según dice, a copiar "los objetos que se nos of recen a la vista, sin lisonjearlos ni ofenderlos". O muy semejantes eran tales objetos en Lombardía y Castilla o, lo que me parece más probable, Cadalso sí conocía la versión literaria del giovin signore pariniano.

La sátira $A$ Claudio. El filosofastro, de Leandro F. de Moratín, señalada también por Menéndez Pelayo al referirse al influjo de Parini, nada tiene que ver en su planteamiento, estructura y concepción, salvo el endecasílabo suelto, con el Giorno. Detalles aislados como el "tazón chinesco / rebosando de hirviente chocolate", nada justifican. Si acaso, el pensamiento de que "por este / sorbo llenamos de miseria y luto / la América infeliz" (puesto aquí en boca del pedante criticado), puede recordar los versos del Mattino donde se cuenta que Cortés y Pizarro no estimaron sangre humana la ultramarina para poder dar nuevas delicias al paladar del noble.

Es fina la observación, aunque tampoco demasiado convincente por su levedad, en torno a una reminiscencia pari-

55. Cadalso, Carlas Marruecas. Prólogo, edición y notas de Juan Tamayo y Rubio. Madrid, Clásicos Castellanos, 1935, pág. 169. Quien estableció algunos paralelos de actitud entre Parini y Cadalso, pero sin considerar el significativo párrafo citado, fue Ernesto Lunardi, La crisi del Seltecento, José Cadalso, Génova, Romano Editricc Moderna, 1948. 
niana de la oda II Messaggio (1795) en la de Moratín A los colegiales de San Clemente de Bolonia (1796), apuntadi por Meregalli. ${ }^{56}$ En síntesis, Parini se dirige al "sciocco vulgo" para preguntarle por qué murmura y cuenta por los dedos el número de vueltas que dio Febo desde su naci. miento. El parecido moratiniano sólo es aplicable a los trea primeros versos:

$$
\begin{aligned}
& \text { ¿Por qué con falsa risa } \\
& \text { me preguntáis, amigos, } \\
& \text { el número de lustros que cumplí? }
\end{aligned}
$$

16.-Si pretendemos, sin embargo, dejar a un lado las hipótesis e impresiones, siempre discutibles, convendría establecer cuál era el grado del conocimiento del poeta italiano a través de datos objetivos. Infructuosa ha sido la búsqueda de su nombre en los tratados de poética, de critica o en las opiniones de los literatos pertenecientes a la segunda mitad del siglo XVIII. Pero en los que visitaron o vivían en Italia en la última década, ya hemos hallado algún testimonio. El P. Juan Andrés escribe a su hermano Carlos una serie de cartas en 1791, publicadas dos años después, sobre su viaje a varias ciudades italianas. En Milán visita naturalmente el famoso colegio de Brera, del que describe sus tesoros, señalando además que "vive también allí el famoso poeta abate Parini, profesor en aquellas escuelas, y autor de poesías originales, que le hacen respetar en toda Italia, y aplaudir como uno de los príncipes de la moderna poesía". ${ }^{57}$

Del único poeta de quien no podemos dudar que le conociera e incluso personalmente es de Moratín, que nos

56. Storia delle relazioni, op. cit., pág. $96 \mathrm{n}$.

57. Cartas familiares, op. cit., IV, pág. 76. Más adelante, en otra carta del mismo año, se limitará a llamarle "el gran poëta Parini" (página 198). 
ha dejado hasta un breve retrato físico: "Fuí a visitar al abate Parini, profesor de bellas letras en este colegio, que ha adquirido reputación por sus poesías, hombre de más de cincuenta años, alto, estropeado de piernas, gesto avinagrado: le sorprendió el motivo de mi visita". ${ }^{58}$ Confieso que de no ser por los rasgos personales tan bien captados (su conocida cojera que le inspira la oda $L a$ cad $t$. ta y su aspecto grave) era para dudar de la visita, ya que lo demás parece casi repetición de lo dicho por el P. Andrés, a quien Moratín visitó por entonces, en 1793, y porque Parini tenía ya en esa época 64 años.

Sólo por afán de agotar las escasas alusiones, merece la pena mencionar al oscuro Nicolás de la Cruz que, en su viaje por Italia, consigna al hablar de los profesores del Gimnasio de Brera: "Parini tiene reputación de gran poeta". ${ }^{9}$

Una última referencia, la más significativa y prácticamente ignorada. En torno a 1833, un desconocido escritor italiano, Antonio Cazzaniga, viene a España y visita a Manuel José Quintana. Su conversación versa naturalmente sobre literatura, de la que el visitante nos dejó esta inapreciable prueba referida al español: "Mi parlò assai di Parini come del piú grande poeta dei tempi moderni, e mi recitò per intero la sua ode La Caduta" ${ }^{60}$ Esto sí que es una declaración probatoria, de conocimiento directo y de estima. Pero ello confirma también que Parini no fue verdadera-

58. Viaje de Italia, en Obras póstumas, cit., I, pág. 313. Merece la pena transcribir su explicactén del porquét de la sorpresa de Parini: "Los españoles yiajan poco, y los que to hacen, no suelen acostumbrar a dar molestia con su presencia a los hombres de mérito que hallañ al paso: ¿para qué? ¿no basta visitar al banquero?

59. Viaje de España, Francia e Italia, Madrid-Cádiz, 1806-1813. Aunque Farinelli, Italia e Spagna, op. cit., pág. 303, lo atribuye al "primo decennio dell'800", es, como máximo, de 1798, razón por la cual da como vivo a Parini.

60. Joseph G. Fucilla, Una visita di Antonio Cazzaniga a José Manuel Quintana, en "Quaderni Ibero-Americani", n." 15 (1954), pág. 400. 
mente valorado en España hasta que alcanza auge el neocliasicismo poético que, en su más riguroso sentido, pertenece más al siglo XIX que al anterior.

De haber alcanzado una difusión que no nos consta, tendría que haber ocupado aquí un lugar importante el jesuita expulso montañés Antonio Fernández Palazuelos, el único que intentó la traducción de las primeras partes del Giorno pariniano con el título El Magisterio irónico del Cortejo o el Chichisveo del célebre Abate Parini, en 1796. Existe un ejemplar impreso en la Biblioteca de Menéndez Pelayo, pero el crítico santanderino sospecha que estas versiones "aunque impresas, no llegaron a ser publicadas, esto es, a circular". Lo afirma así porque no tienen portada y por su rareza, ya que Menéndez Pelayo sólo tenía noticia del ejemplar de su biblioteca.$^{61} \mathrm{La}$ apreciación no es del todo exacta, ya que al menos en la Marciana de Venecia existe otro ejemplar del Magisterio irónico. Pero como sí es indudable que no fue por entonces divulgada, no pudo tener peso alguno sobre la literatura española de la época. Este hecho indudable. el estudio ya existente de Menéndez Pelayo y mi intención de publicar y estudiar por separado la traducción de Palazuelos, me relevan de dedicarle más espacio en estas notas.

17.-Unas conclusiones muy breves, que sirvan para aunar afirmaciones dispersas, se hacen necesarias. La fisonomía peculiar de la España de los últimos decenios del Siglo XVIII es consecuencia de un cruce de corrientes anto ideológicas como artísticas, entre las que no hay que olvidar la persistencia de elementos tradicionales españoles. Que España, a pesar de las barreras que a ello se oponían, estaba ansiosamente abierta al exterior es indudable. Pero una cosa es contactos más o menos intensos y otra efectivos in.

61. Estudios y Discursos, op. cit., VI, pág. 13. 
flujos. El intercambio con el grupo de reformadores, sabsw todo en el ámbito económico-jurídico, está comprobado. La lectura, la existencia en las bibliotecas públicas y privadas de los grandes autores clásicos italianos, es un hecho de. mostrable. Pero su profunda significación era la de contrapeso al mal gusto, la de su reconocido prestigio formal. Era natural, por tanto, que Dante, con su genial capacidad de creación lingüística, no figurara entre ellos. Petrarca, en cambio, se lleva la palma. De los autores del Cinquecento, puede sorprender a primera vista que el tormento y el claroscuro espiritual y expresivo de Torquato Tasso hayan prevalecido con mucho sobre la ya tópica armonía ariostesca. Pero se comprenderá inmediatamente este fenómeno tenierıdo en cuenta la vena melódica, íntima y sentimental que alienta en la característica sensibilidad de la segunda mitad del siglo XVIII.

Con Petrarca y Tasso, a través de Chiabrera, llegamos al primer nombre representativamente setecentista que ha dejado profunda huella en el gusto de la época: Metastasio. Pero la influencia de Metastasio pertenece más bien a la historia de la vida social, de las costumbres, de las modas. En medio, sin embargo, de la difusa simpatía melódico-formal que despertó y junto con algunos aislados aciertos expresivos, es de justicia señalar una conquista importante que a su devoción se debe: la octavilla italiana. El mismo Zo. rrilla confesará muchos años después a Leopoldo Alas que aprendió esta estrofa en Arriaza, en su traducción de la fa. mosa canzonetta metastasiana. ${ }^{62}$

62. "¿Qué poeta cree usted que fue el que despertó mi instinto poético y cuyas composiciones estudié el primero? Pues fue Arriaza, y mi afición a las octavillas octosílabas viene de las de su traducción de la "Despedida de Metastasio". Lo primero que yo escribí a los doce años fue una imitación de aquéllas... Así sali yo difuso y vacío "octavillista". La importante carta, fechada en "Berna, 25 mayo 84", fue publicada por Luis Araujo-Costa, Zorrilla. Arriaźa y "Clarin", en "El Español", del 15 de febrero de 1947. 
La presencia en los escenarios españoles de Goldoni se limita en un principio a un aspecto limitado: el jocoso-musical. Las comedias vienen a fines de siglo, cuando hay nuevos ideales en el ambiente. Nadie ha podido demostrar verdadero influjo en autores determinados ni modalidades especiales en el género de la comedia a él debidas. Alfieri sí condicionó un tipo de teatro, más en su ideología que en su técnica dramática. Pero es problema que pertenece ya al siglo XIX. Y algo semejante cabe decir de Parini, del que no nos consta que haya sido conocido antes del último decenio del siglo y que sin duda era ya bien leído, como un clásico, en los albores del romanticismo. Sólo Cadalso parece haber tenido clara noción del contenido del Giorno, pero no como estímulo de inspiración poética. Y que haya sido fuerza impulsora de actitudes, lengua o estilo en Jovellanos y Moratín, es a su vez muy discutible.

¿Hasta qué punto puede, pues, afirmarse que la España dieciochesca haya sido sirvienta fiel ("fida ancella", como decía Farinelli) de la literatura italiana? Distingámoslo una vez más: una cosa es difusión, presencia, conocimiento y hasta reconocimiento de cultura modélica, paradigmática, arquetíicica. Y otra cosa muy distinta que haya determinado corrientes vivas de poesía, que haya suscitado cambios de gusto, que haya impuesto nuevas formas, estructuras o géneros. Junto a la toma de contacto indudable con la ideología de los reformadores y a la afición despertada en la buena sociedad por el teatro musical, en el orden rigurosamente. literario sólo podemos mencionar un afortunado logro métrico debido al prestigio de Italia: la octavilla, justamente llamada italiana. 